\title{
La imagen adolescente del mundo en Angelitos empantanados de Andrés Caicedo
}

Patricia Vilcapuma Vinces

pvilcapuma@ucss.edu.pe Universidad Católica Sedes Sapientiae

Fecha de recepción: septiembre de 2014

Fecha de aceptación: octubre de 2014

Resumen: En este trabajo se analizará la imagen «adolescente» del mundo propuesta en la obra Angelitos empantanados (1977) de Andrés Caicedo mediante la visión de los personajes adolescentes. Esta imagen adolescente del mundo que proyectan sus personajes es una respuesta a lo que «reciben» del mundo adulto, por lo que las acciones que se ven obligados a realizar finalmente se vuelven expresiones antiadultas frente a lo que les pide ese mundo «adolescente» que subyace a la realidad que ellos perciben. Absortos ante una ciudad, Cali, que se les presenta como un espacio que no termina por consolidarse totalmente y que los condiciona incluso en su libertad, estos angelitos se sumergen cada día en el submundo. Así, la trilogía que compone esta obra propone el conflicto adolescente como el preludio a un permanente estado en el ser humano que se caracterizará por lo siguiente: (a) la automarginación y la autodestrucción; (b) la búsqueda del placer vinculada a la transgresión del amor y del cuerpo; (c) la ausencia y desprestigio de la autoridad familiar; (d) la imposibilidad del entendimiento mutuo de los grupos humanos y sus respectivas culturas, ya que ambos siguen su destino: condenados por sus circunstancias; y (e) la fatalidad como condición de la existencia. 
Palabras clave: Andrés Caicedo, personaje adolescente, ciudad, literatura colombiana, literatura juvenil.

\title{
The adolescent view of the world in Andrés Caicedo's Angelitos Empantanados
}

\begin{abstract}
In this work an "adolescent" image of the world in Andres Caicedo's Angelitos empantanados (1977) book will be analyzed through the view of adolescent characters. This adolescent opinion of the world that the characters project is a response to what they "receive" from the adult world. That is why the actions they are finally forced to perform become anti-adult expressions in relation to what the "adolescent" world in which the underlying reality they perceive exists. Absorbed in the city, Cali is a place that is still consolidating and yet constrains them from their freedom. These little angels are immersed in the underworld. Thus, the trilogy that constitutes this writing regards the adolescent conflict as the prelude to a permanent state in the human being that will be characterized by the following: (a) self-exclusion and self-destruction; (b) the search of pleasure associated to love and body transgression; (c) absence and disrepute of family authority; (d) lack of mutual understanding among human beings and cultures since they follow their destiny: they are sentenced by the circumstances; (e) fatality as an existence condition.
\end{abstract}

Keywords: Andres Caicedo, adolescent character, city, Colombian literature, youth literature.

\section{A AndréÄBuckcqhuer}

\section{Introducción}

En este trabajo se expondrá acerca de la imagen adolescente del mundo creada por Andrés Caicedo mediante la visión de sus personajes adolescentes. Se analizará y comentará la obra del colombiano titulada Angelitos empantanados (o historias para jovencitos) (1977), compuesta por los relatos «El Pretendiente», «Angelita y Miguel Ángel» $\mathrm{y}$ «El tiempo de la ciénaga», en la que los jóvenes que la protagonizan parecen estar condenados al desarraigo y la degradación en la ciudad de Cali, escenario de sus historias. Esta ciudad, representada por una compleja sociedad colombiana de la década del 60 e inicios de la del 70, se les rebela como un espacio que no termina por delimitarse o asentarse totalmente, y los condiciona incluso en su libertad, 


\section{LA IMAGEN ADOLESCENTE DEL MUNDO \\ EN ANGELITOS EMPANTANADOS DE ANDRÉS CAICEDO}

que no les da derecho ni a una identidad singular ni relacional. Por ello, estos angelitos caminan por los márgenes o se sumergen cada día en un submundo como una forma de evasión de una realidad en la que de cualquier forma, según expresan dichos personajes, les aguarda un destino fatal.

Paradójicamente, este autoexilio físico y mental al que se someten los personajes caicedianos, se convierte en un "furibundo silencio» que representa y proyecta una visión de mundo. Se trata de una visión que, más allá de testimoniar la época convulsa política y cultural que vivía la juventud colombiana y latinoamericana (Cf. Echeverry 1978; Henao Restrepo 1982; Ospina 1988; Martá, Martínez y Sánchez 2012), denuncia y augura de alguna manera la situación del hombre actual: un optimismo "pesimista» ante el extravío del significado de su existencia y, a la vez, un reclamo urgente por encontrar un nexo con la realidad. En otras palabras, la desazón o el desencanto que manifiestan en la forma que tienen estos personajes de asumir la existencia en el mundo narrativo recreado por el colombiano es un ensayo y premonición de la realidad de la juventud actual: desamparo espiritual de los jóvenes (Cf. Echeverry 1978), proceso de lumpenización (Cf. Henao Restrepo 1982), apelo a la autodestrucción (Cf. Ospina 1988), entre otros.

La obra de Caicedo, en este sentido, como dirían sus críticos, «es un recurso narracional acusador y denunciante despiadado, con el papel exclusivo de arreglar un mundo mostrando sus llagas con el dedo... [Caicedo] es un apolítico pero crítico de su régimen social» (Echeverry 1978: 7). Asimismo, Caicedo fue representante de «esa inteligente e inconforme juventud caleña que quisieron por medio del arte crear conciencia sobre la realidad nacional» (Carvajal Córdova 2007: 86). Así, «no cabe duda que su insatisfacción e inconformidad lo convierten en un ser que trabaja en el arte y para el arte con el fin de manifestar todo el peso y la desesperanza que le oprimía en una época de rupturas, de liberación juvenil y estudiantil de los años 60 y 70» (Carvajal Córdova 2007: 85).

\section{El «Atravesado» Caicedo}

El joven escritor colombiano, a quien vivir más de 25 años le parecía un absurdo, será una especie de bomba de tiempo en su ciudad. Como ya mencionamos, sus relatos testimonian la corrosión del mundo y la indiferencia con un sector vulnerable, pero importante en tránsito hacia el mundo adulto. Los críticos Sandro Romero Rey y Luis Ospina (2008), editores de su obra, la mayoría póstuma —Caicedo acabó él mismo con su vida—, manifiestan 
claramente acerca del universo narrativo del colombiano que «la incertidumbre de las nuevas generaciones es como cualquier párrafo que describe a los angustiados personajes caicedianos. Por esta razón, los textos inéditos de Andrés salen a la luz, no solamente por capricho generacional, sino por una necesidad histórica» (2008: 23).

En efecto, el joven Caicedo es él mismo casi un personaje de toda su obra, víctima y condenado a perderse sin punto de arraigo, de espalda al porvenir porque la ciudad, el mundo, que recibe a sus nuevos habitantes le da la más brutal de sus bienvenidas: tiene que ser útil a la sociedad según sus costumbres y tradiciones. ¡Y a qué sociedad! Él ha recibido una buena educación, su familia de clase media lo procuró, como el mismo declara, de «gustos y favores». Sin embargo, el sistema social (la familia, el trabajo, la subsistencia...) no ofrecía un soporte al deseo de la propia humanidad, sino que condicionaba por todos lados la manera de vivir. En el volumen El cuento de mi vida (2008), compilación de muchas de sus reflexiones personales, Caicedo lo reafirmará; primero, respecto a su familia:

[...] Anda y te buscas una vida, sé como tus hermanos, cásate, procrea, sé útil a la sociedad. Ellos nunca me han tomado en serio una vez que fui creciendo y fui descubriendo los motivos por los cuales tenía que rechazar su cuidado, ese que ahora no digamos necesito, ese que ahora añoro porque en él está la clave de cómo comencé a perderme. (Caicedo 2008a: 52)

Segundo, respecto al trabajo, el de su padre:

¡Pero si ya tiene cincuenta ańos, es lo que digo yo! Y tener que trabajarle todavía a unos ricos, esto es lo que le seguiré criticando siempre, haber vendido su fuerza de trabajo hasta el agotamiento y ser tan conformista; está tan del lado de los que han andado con él, digo, han hecho vida social con él y su esposa, pero nunca le han ofrecido otra oportunidad distinta a la explotación. Es el dilema, la agria tragedia de la clase media. (Caicedo 2008a: 53-54)

Tercero, y de manera concluyente de la experiencia que tiene en su corta vida: «Ahora sé que la originalidad está prohibida, que hay que hacer las cosas según el patrón, mientras más establecido, mejor» (Caicedo 2008a: 82-283). A partir de estas vivencias, Caicedo refundará su propio universo mediante la literatura en respuesta a todo lo que desdeña de su ciudad y lo que esta representa. 


\section{LA IMAGEN ADOLESCENTE DEL MUNDO \\ EN ANGELITOS EMPANTANADOS DE ANDRÉS CAICEDO}

Es así que toda su obra tiene como contexto la ciudad de Cali. Dicho espacio es asumido, según sus críticos:

Como una especie de metáfora de su propia vida, entendiendo la caleñidad como una excepción, como una salida por la puerta trasera, como un reto. La capital del departamento del Valle del Cauca ha sido un medio donde la vida cultural se ha arrastrado para tratar de imponerse, y las expresiones juveniles [...] han tenido una salvaje, agresiva e inteligente manera de cuestionar las normas establecidas, a través de todos los excesos posibles, llámese cinefilia, erudición, drogas, pasiones irrefrenables o soluciones radicales. (Romero Rey 2007: 35)

\section{Cali, el mundo de Caicedo}

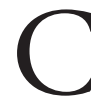
ali, capital del Valle del Cauca, siempre ha sido un espacio en el que las manifestaciones juveniles han irrumpido agresiva e inteligentemente para cuestionar las reglas mediante todos los excesos posibles (Cf. Romero Rey y Ospina 2008b); una ciudad solo para adolescentes, según afirmación del propio Caicedo (Romero Rey y Ospina, 2008b); escenario del auge de los movimientos estudiantiles (Martá, Martínez y Sánchez, 2012); una ciudad de «festivales de arte, música go-go y ye-ye, nadaistas y estudiantes que tiraban piedra» (Romero Rey 2007: 22).

La década del 70 estuvo marcada para los habitantes de Cali y para toda Colombia. El 26 de febrero de 1971, a pocos meses de la inauguración de los VI Juegos Panamericanos —y por lo que se bautizó a Cali «Ciudad de América»—, la policía caleña responde con beligerancia a una manifestación estudiantil. El resultado fue un reguero de muertos y heridos en las calles; entre ellos un universitario, Eduardo Mejía, apodado Jalisco, quien pasa a convertirse en el símbolo de un movimiento contestatario contra una sociedad incapaz de comprender los interrogantes de la época.

Y así lo sintió Caicedo:

Con todo, los Juegos se celebran y dejan una imagen de bienestar, lujo y bonanza [...] Con 20 años, Andrés Caicedo amigo de [los cineastas] [Luis] Ospina y [Carlos] Mayolo, con quienes abanderaría una de las más lúcidas vanguardias contestarías que diera Colombia en los setenta, recoge el espíritu de los tiempos y escribe: “[...] Que di piedra y me contestaron con metralla [...] Que no hay caso, mi conciencia es la tranquilidad en pasta, por eso soy el que tira la primera piedra”. (Patiño Millán 2008: 10-11) 
En efecto, una muestra es su obra Angelitos empantanados (o historias para jovencitos). Esta es hasta ahora una piedra lanzada por Caicedo a la cara de una ciudad que parece condenar a sus habitantes más jóvenes a un submundo de profundas contradicciones y confusiones acerca de lo que es ser humano. Esta contiene una imagen adolescente del mundo que proyectan sus personajes en respuesta a lo que «reciben» del mundo adulto, por lo que las acciones que se ven obligados a realizar son expresiones antiadultas frente a lo que les pide ese mundo adolescente que subyace o se subyuga a la realidad que ellos perciben.

\section{El mundo empantanado de los angelitos}

a ciudad de Cali, tomada por la narrativa de Caicedo, ve transitar por sus calles a
unos jóvenes «empantanados», arrojados al mundo y condenados por ello a un orden ya establecido. A estos jovencitos, Caicedo les da voz, les da «la piedra» para lanzar; estos «angelitos» rechazan el éxito burgués y su estructura familiar, cuya falta para algunos constituiría la principal causa de perdición. Sin embargo, las comodidades, el orden del mundo adulto que los rodea no tienen un atractivo para estos adolescentes, porque no hace más que exponerlos a una sobredosis de hipocresía y orfandad moral:

La locura, la soledad el hastío, la nostalgia, la embriaguez [...] de varios personajes [...] representan de algún modo una forma de evasión de la realidad; ellos no quieren aceptar ni menos compartir las costumbres y tradiciones de su medio social; parece ser que la postura indiferente que asumen frente a los adultos no es la solución y por ello deciden desaparecer ya sea física o mentalmente de ese mundo que no toleran. (Martá, Martínez y Sánchez 2012: 138)

El pretendiente, Angelita Rodante, Miguel Ángel, así como otros personajes del universo narrativo caicediano en Angelitos empantanados (o historias para jovencitos), tratan de delimitar sus espacios en una ciudad que cada día inaugura autopistas o construye edificios, y va despojando de su mundo adolescente los pocos paisajes naturales que han podido conocer en su corta vida. Así como la ciudad va perdiendo su naturaleza, ellos también van perdiendo la propia, al abandonarse o a sus emociones o al tedio de una vida sin sentido, "como únicos sobrevivientes de la gran tragedia», (Caicedo 2008c: 48), a decir de El Pretendiente; o ante la gratuidad de la vida, responder con una especie de parálisis 


\section{LA IMAGEN ADOLESCENTE DEL MUNDO \\ EN ANGELITOS EMPANTANADOS DE ANDRÉS CAICEDO}

que les impide abrazar la belleza de la realidad y mucho menos trascenderla. Y cito en este punto a uno de sus personajes, Antonio Rodante: «Esta exuberante vegetación, esta libertad [...] no hacen más que recordarme mi mortandad, hasta el punto que mis días son una interminable espera de la vejez» (Caicedo 2008c: 56-57).

Podemos decir, asimismo, que más que una respuesta rebelde ante lo que no tienen al alcance, en esta obra, los personajes adolescentes asumen una especie de optimismo "pesimista». Valga el oxímoron para ilustrar su postura ante el extravío del significado de su existencia y que, a la vez, constituye un reclamo urgente por encontrar un nexo que los una a la positividad de la vida, que intuyen, pero que apenas pueden entender, ya que se encuentran inmersos en una imagen del mundo negativa que los arroja a la desolación y a la violencia. Así, este reclamo, por ejemplo, se refleja en el pensamiento de otro personaje, Mico, que si bien no pertenece al grupo privilegiado, al involucrarse con este, también acaba aceptando el papel en el que se le ha ubicado y, por lo que, a pesar de las simpatías, termina, ayudado por sus amigos, asesinando a los personajes principales de esta historia. El narrador refiere sobre él: «Se imaginó un estado de cosas en donde la gente fuera invulnerable al dinero, en donde la gente no tuviera dinero para derrochar, para ofrecer semejante recompensa, para que la gente buena [como él] perdiera por ella su valor, su dignidad» (Caicedo 2008c: 138).

Por otro lado, la ideología burguesa que rodea su ambiente hace que respondan con hastío a una situación heredada de un sistema familiar-social que es irracional a sus ojos. Lo sostendrá el personaje-narrador del tercer relato titulado «El tiempo de la ciénaga», el tiempo pantanoso. «Lo que pasa es que tengo que acomodarme a la tristeza, o aceptar que la desesperación es la única vía de acceso a todo en este nuevo día» (Caicedo 2008c: 119).

Las tres historias de Angelitos empantanados parecen responder al intento de su autor de ensayar posibilidades de salida y sobrevivencia en un mundo sin encanto. Son historias de jovencitos: la historia de «El Pretendiente», «Angelita y Miguel Ángel», y «El tiempo de la ciénaga» se resume a enamoramientos, amistad, rebeldía, incapacidad para admitir la vida. Ninguno se salva de la devastación real de la imagen del mundo que se proyecta.

Todo ello tan solo sirve de escenario para el planteamiento de fondo del autor, la deshumanización progresiva, la caída de los «angelitos». La trilogía que compone esta obra propone el conflicto adolescente como el preludio a un permanente estado en el ser humano que se caracterizaría por lo siguiente: 
- La automarginación y la autodestrucción. El Pretendiente adopta esta actitud en respuesta a su imposibilidad de ser aceptado por otro, en este caso, se corrompe en la medida que acepta el rechazo amoroso de Angelita.

- La búsqueda del placer vinculada a la transgresión del amor y del cuerpo. La relación pasional de Miguel Ángel hacia la prostituta Berenice, que comparte con sus compañeros de escuela, y su apropiación de esta mediante la muerte y la conservación de partes de su cuerpo.

- La ausencia y desprestigio de la autoridad familiar como se muestra en las referencias que hacen los personajes a sus padres.

- La imposibilidad del entendimiento mutuo de los grupos humanos y sus respectivas culturas, ya que ambos siguen su destino: condenados por sus circunstancias. En «El tiempo de la ciénaga», los personajes se desplazan del norte, la zona acomodada, al sureste, espacio marginal y entablan allí relaciones con tres adolescentes. A pesar de que se produce un aparente entendimiento, los jóvenes pobres asesinan a los jóvenes del barrio acomodado sin más explicación que la del personaje-narrador, quien los califica como «raza de perdedores» (Caicedo 2008c: 140).

- La fatalidad como condición de la existencia. Además de lo que sucede en cada personaje, esto se ve, por ejemplo, en el personaje Angelita, que aparece en los tres relatos. Sea cual sea su historia termina o sufriendo por amor, o asesinada, o muerta por decisión propia.

\section{Conclusiones}

$Z^{n}$ esta lectura se partió de la premonición que representa la obra de Caicedo acerca Cde una situación presente en la sociedad actual: un autoexilio que concluye con la progresiva deshumanización frente a la posibilidad de encontrar un nexo con la realidad. $\mathrm{Su}$ obra es un recurso que denuncia mediante los personajes adolescentes de Angelitos empantanados la visión de un mundo "adolescente» desconcertante. Asimismo, construye una narrativa antiadulta con un fondo de sobreexposición del vacío de la juventud. «Ese vacío es el presente, el eterno presente, que ha de vivirse cuando no hay alternativas ni hacia el pasado ni hacia el futuro, para lo cual hay que combatir al adulto en todas sus manifestaciones» (Cárdenas Páez 2006: 14). 


\section{LA IMAGEN ADOLESCENTE DEL MUNDO \\ EN ANGELITOS EMPANTANADOS DE ANDRÉS CAICEDO}

Caicedo adopta Cali como fondo para sus historias. Presenta a sus personajes inmersos en una ciudad en crecimiento, y estos padecen las consecuencias de su modernización. Aunque por momentos la ciudad que habitan les ofrece retazos de un espacio en el que aparentemente superan la búsqueda de su inhallable identidad, al final esta termina creando su soledad. Los personajes del colombiano «son muchachos incrustados en su juventud, pasmados en esa época en que se tiene los años frescos y los cuerpos ágiles pero en una felicidad desgarradora» (Valencia 1985: 17, las cursivas son nuestras).

Sin embargo, es posible que su obra como tal establezca un nexo positivo con la realidad, en el sentido que se constituye una llamada de atención sobre lo que el mundo adulto ofrece, sostenido en el sistema social al que todos deben pertenecer - el de la madurez, el orden, el crecimiento-, pero que no resulta atractivo. Los adolescentes de Caicedo intuyen la necesidad de mirar adelante, de frente, de querer vivir dignamente. El Pretendiente, personaje caicediano de Angelitos empatanados, permite mantener esa aseveración:

¿Qué me llevó a caminar hasta bien al norte por la autopista nueva? [...] Puede que haya sido la desesperación ante un crepúsculo terrible cuando yo no pretendía otra cosa que hacer durar el día. [...] Miré a lado y lado de la pileta y me provocó el verde. Caminé al Oeste porque prefiero las montañas. Al encontrarme aquel camino de ciruelos me doblé (y casi me desplomo) ante una punzada de cariño: hacía mucho que no veía un árbol tan cerca de la ciudad; me abandoné al impulso que un instante antes me reprimiera [...]. (Caicedo 2008c: 46)

Las punzadas de cariño todavía son posibles sentirlas en medio de la desolación que deja la pérdida de lo esencial; en este pasaje — como en otros del volumen — vemos una vez más que los espacios de confort de los adolescentes de Caicedo son los pocos del campo que quedan en la ciudad, y que se van contaminando o destruyendo por las nuevas edificaciones. Así también, simbólicamente, sucede en su «espacio» interior que se va contaminando con lo que representa para ellos su ingreso al mundo adulto. Sin embargo, estas reflexiones y actitudes contemplativas hacia el paisaje por parte de los personajes (El Pretendiente, Mico, el adolescente de «El tiempo de la ciénaga», Angelita, Antonio Rodante, entre otros) pueden ser indicios de un deseo interior por no desarraigarse del todo, porque hay una posibilidad de ser y desarrollarse. Es decir, puede haber otros caminos, aquellos mediante los cuales es 
posible que el adolescente confronte sus circunstancias con lo que verdaderamente anhela, y que pueden sacarlo de la oscuridad, de su imposibilidad para ser hombre, «adulto».

Por otro lado, la obra de Caicedo en sí misma testimonia la tarea del escritor y su compromiso con el mundo. Su escritura refleja lo que sostiene Sábato en relación de la naturaleza de creación artística: «La tarea del escritor sería el entrever los valores eternos que están implicados en el drama social y político de su tiempo y lugar [...] Pues si es profundo, el artista inevitablemente está ofreciendo testimonio de él, del mundo en que vive y de la condición humana del hombre de su tiempo y de su circunstancia» (Sábato 1984: 81).

El compromiso de un autor puede ser explícito o implícito. Este último es el caso de Caicedo, ya que desde el momento que se da el proceso de creación artística es una voz que interpela a la realidad: se adhiere a ella, la niega, o se rebela contra ella. La imagen adolescente del mundo que las obras de Caicedo nos representan corresponden justamente a un sentir, de un contexto muy propio, pero que por la fuerza de su denuncia el lector no puede quedar indiferente.

Desde que un autor se propusiera denunciar lo que todos parecemos reconocer, pero que nos es indiferente por vivir al refugio de sistemas, ideologías, en las que no tenemos la responsabilidad de ver implicado lo que somos como seres humanos (Cf. Giussani 1990), nos devuelve la esperanza de encontrar un sentido. Si estamos atolondrados por el bullicio de la ciudad o adormecidos por una sobreexposición a la cultura dominante, la narrativa de Caicedo testimonia, aunque parezca lo contrario, que «[...] el hombre desde siempre, y más profundamente de cuando ha advertido sus otras necesidades, ha vivido la urgencia de interrogarse y no dejar sin respuesta la pregunta sobre el fin último de su caminar» (Giussani 1990: 12).

Finalmente, Caicedo decidió salir por la puerta trasera, se suicidó a los 25 años. Tuvo una vida agitada, hasta desequilibrada; su sensibilidad lo hizo más aprehensivo a la violencia de su sociedad. «Sus textos son excesivos, desmesurados, histéricos, comprometidos y tercos, pero allí hay cuenta de una época y sobre todo, de un ser humano irrepetible» (Romero Rey 2007: 29). Desanimado de la vida sí, pero no por ello se negó la oportunidad de buscar ese algo que por momentos le permite una conexión sintónica con el mundo. Sus obras lo demuestran, y sus «angelitos empantanados» lo acompañaron. 


\section{LA IMAGEN ADOLESCENTE DEL MUNDO \\ EN ANGELITOS EMPANTANADOS DE ANDRÉS CAICEDO}

\section{REFERENCIAS}

Caicedo, Andrés

2008a El cuento de mi vida. Bogotá: Norma.

2008b Calicalabozo. Bogotá: Norma.

2008c [1977] Angelitos empantanados (o historias para jovencitos). Bogotá: Norma.

Carvajal Córdova, Edwin

2007

Estudio previo y edición crítica de la obra narrativa y dramática del escritor colombiano Andrés Caicedo. Tesis doctoral, Universidad de Granada, Granada, España. Disponible en <http://www.tdx.cat/handle/10803/16104>.

CÁrdenas Páez, Alfonso

2006 Prólogo. En Jiménez Camargo, Camilo. Literatura, juventud y cultura posmoderna. La narrativa antiadulta de Andrés Caicedo. Bogotá: Fondo Editorial de la Universidad Pedagógica Nacional, pp. 9-16.

Echeverry, Ana Cecilia

1978 Andrés Caicedo: literatura de música y droga. Tesis de licenciatura. Universidad del Valle. Cali, Colombia.

Giussani, Luigi

1990 La conciencia religiosa del hombre moderno. Madrid: Encuentro.

Henao Restrepo, Darío

1982

El lumpen de la literatura. Análisis de «Bomba Camará» de Umberto Valverde $y$ "Que viva la música de Andrés Caicedo». Tesis de licenciatura. Universidad del Valle. Cali, Colombia.

Martá, Diana; Martínez, Carlos, y Carolina Sánchez

2012 El teatro de Andrés Caicedo, expresión de su conflicto psíquico. Tesis doctoral, Universidad de La Sabana, Bogotá, Colombia. Disponible en <http:// intellectum.unisabana.edu.co:8080/jspui/handle/10818/4578>. 
Ospina Silva, Barney

1988 Aspectos sociales de la obra de Andrés Caicedo. Tesis de licenciatura. Universidad del Valle. Cali, Colombia.

Patiño Millán, Carlos

2008 «Una hermosa modelo que se convirtió en vampiro». En CAICEDo, A. Angelitos empantanados (o historias para jovencitos). Bogotá: Norma, pp. 9-18.

Romero Rey, Sandro

2007 Andrés Caicedo o la muerte sin sosiego. Bogotá: Norma.

Romero Rey, Sandro y Luis Ospina

2008 «Invitación a la noche». En CAicedo, A. Calicalabozo. Bogotá: Norma, pp. 7-37.

SÁbATo, Ernesto

1984 El escritor y sus fantasmas. Buenos Aires: Seix Barral.

Valencia, Rodrigo

1985 Cine, música y droga en la narrativa de Andrés Caicedo. Tesis de licenciatura. Universidad del Valle. Cali, Colombia. 